\title{
Discrete Element Simulation of Attenuation Law of Blasting Stress Wave
}

\author{
Bin Li \\ Institute of urban construction \\ Nanhua University \\ Hengyang, China \\ lb1667@126.com \\ Wenzhao Chen \\ Institute of urban construction \\ Nanhua University \\ Hengyang, China \\ 756258433@qq.com
}

\author{
Xiqi Liu \\ Institute of urban construction \\ Nanhua University \\ Hengyang, China \\ liuxiqi@sina.com \\ Longbin $\mathrm{Li}$ \\ Institute of urban construction \\ Nanhua University \\ Hengyang, China \\ lilongbin52@163.com
}

\begin{abstract}
The process of rock blasting involves large deformation of rock mass,material nonlinear,and so on, the research on the mechanism of it is still in the stage of exploration at present.This article attempts to analyze the propagating of the stress wave in the explosions from the microscopic view. We simulate the whole transmission process of explosive stress wave,and obtain the change laws between stress wave with the distances from center of explosion on the basis of the previous theoretical analysis and model experiment. And then compared the results of model calculation with the result of this experiment,The result show the applicability of the simulation results.This paper discloses the motion of particles in the blast from the microscopic view, it is helpful for us to study more complicated geotechnical problem in meso-scale simulation, so as to provide experience for reference.
\end{abstract}

Keywords-numerical simulation; explosive stress wave; stress wave peak; stress wave attenuation

\section{INTRODUCTION}

In recent practical engineering projects,blasting is one commonly used methods.Some joint fissure often occurs In the rock mass, which made blasting stress appear some phenomena in the weak structural plane,such as refraction, reflection,waveform conversion complex phenomenon,by changing the wave drag, the strength and other factors of the rock mass.All these will reduce the utilization of blasting energy,and made the Blasting cannot achieve the ideal effect.If we can choose blasting position reasonably,and make full use of the structure and structural characteristics of rock mass,we can not only save a lot of explosives,improve the blasting efficiency,but also can protect the soil excavation,improve the stability of engineering rock mass. The research about the attenuation law of stress wave in different joint under blasting load only has important theoretical significance, also has important value of Engineering application.

Relevant scholars at home and abroad have done some research work, about the influence of joint fissure on blasting stress, in the aspect of theory and experiment.According to the geometric relations between geological faults and joints,using the theory about joint fissure transmitting stress wave,Wang Ming-yang and Qian Qi-hu ${ }^{[1]}$ analyzed the attenuation law when the stress wave through the joint fissure,and the relevant results have important guiding significance for practical engineering.Zhang Ji-hong and Liu Hong-yan ${ }^{[2]}$ analyzed the failure mode of the differences between intact rock and jointed rock by popular unit,it shows that the effect of joint on blasting damage model is mainly associated with the geometric distribution and the physical and mechanical properties of joint.Li Xue-ye ${ }^{[3]}$ not only set up branch damage constitutive relationship,but also derived the analytical solution and studied the law of transmission and reflection when the stress wave transmit irregular joints,and finally the theory expression of the transmission and reflection coefficients and fractal dimension is gained.Abdellah Hafsaoui and Korichi Talhi ${ }^{[4]}$ analyzed and studied the fragmentation distribution by 16 groups of model experiments between different incidence and detonation position, the data show that joint attitude and the explosive position have remarkable influence on the blasting results. Y.Ju ${ }^{[5]}$ gave the relationship of energy consumption and the fractal dimension of joint surfaces from the point of experiment,by three point bending random breaking rock, simulating the natural joint plane,introducing the theory of fractal geometry and describing the joint surface roughness.

Usually,joint exist in a form of cross modal in the actual joint rock,but the research mainly focused on the transmission rules of stress wave in a single or parallel structure surfaces at present.The phenomenon of the multiple transmission, reflection and waveform conversion will happen when the stress wave propagate in the cross joint rock.This not only affects the engineering effect of blasting,also will influence the law of the attenuation of stress wave.So,carrying on further investigation on the law of the stress wave 
propagate in the cross joint rock, we can have theoretical and practical significance,and this is also the meaning of this dissertation.

\section{ESTABLISH DISCRETE ELEMENT MODEL}

\section{A. Simulate Blast Stress Wave}

The explosive stress wave will spread in the form of a spherical under the action of concentrated blasting.In general,we will simplified the spherical wave as plane wave because of the complexity of the spherical wave.Usually, in real project, the changing course of the pressure on the wall of borehole has two kinds of triangular load and exponential load.during the study of structural antiknock, triangular load is widely used due to simple load distribution and describing the basic characteristics of explosion load accurately.According to the general characteristics of blasting,we assume that the ball charge of rock pressure $\mathrm{P}$ (t) relation to time is shown in figure 1.And we simulate blasting action By adoptting the way of applying blast load 1 to blasting-hole wall ,the dynamic load is simplified to simple harmonic waves input by the PFC program.According to the research of blasting model test results(as shown in Figure 1) that experiment in the roadway At the Institute of urban construction, Nanhua University,we take explosion load rise time "tr" for $2 \mathrm{~ms}$, the time of explosive load positive pressure "td" for7ms, the maximum of explosive load "Pb0" for 50Mpa

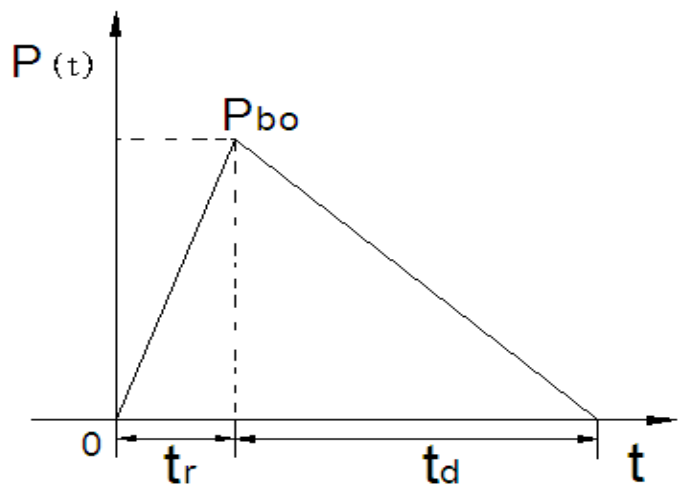

Figure 1. Triangle Pulse Blast Load

\section{B. Study the Micro Parameters of the Models}

According to the blasting model test at the Institute of urban construction, Nanhua University, the model use the mixture of cement and crushed sand with 1:5.23. Then the radial information of the jointed rocks and the blasting can be derived by the inverse algorithms of model simulations. The material of rock mass is simulated to compressive biaxial test by using software PFC2D(as shown in Figure 2, 3, 4.) And we obtain the micro parameters of the model(as shown in table 1,2 )on the basis of parameter sensitivity analysis by back analysis.It's not hard to see that the simulate curve and the test curve has a good agreement in Figure 4.

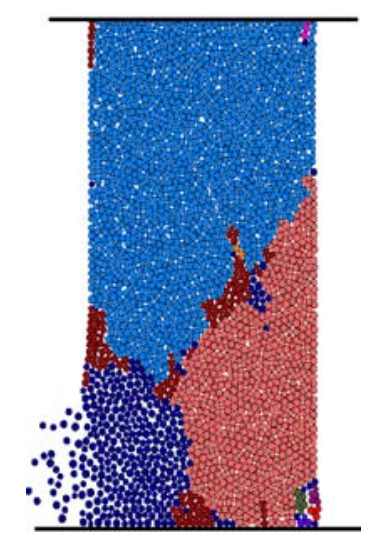

Figure 2. PFC Model

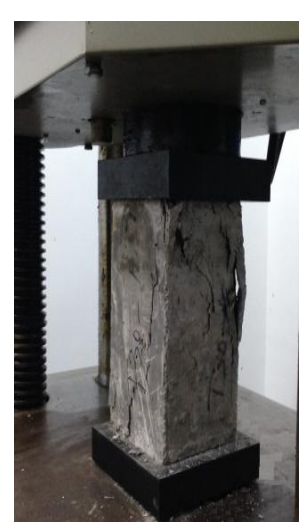

Figure 3. Uniaxial Test

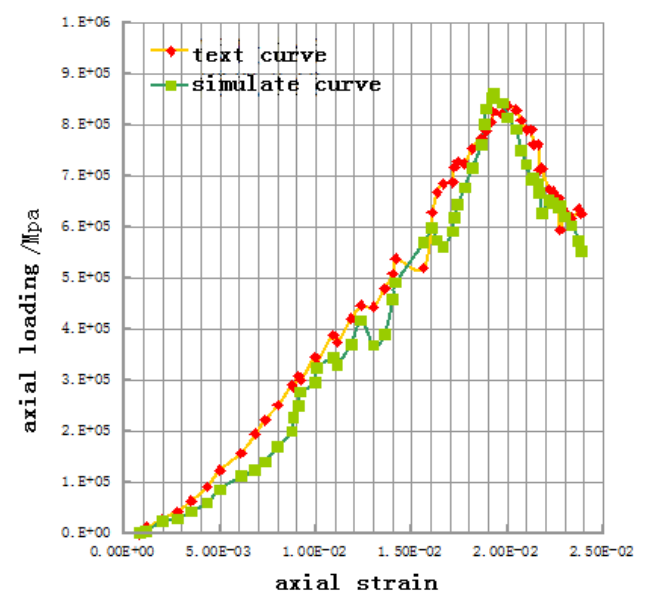

Figure 4. Stress-strain Curve

TABLE I . THE PARAMETERS OF ROCK

\begin{tabular}{|c|c|c|c|c|c|}
\hline $\begin{array}{c}\text { Rock } \\
\text { parameters }\end{array}$ & $\begin{array}{c}\text { Particle } \\
\text { proportion } \\
\mathrm{kg} / \mathrm{m}^{3}\end{array}$ & $\begin{array}{c}\text { Particle } \\
\text { radius } \\
/ \mathrm{mm}\end{array}$ & $\begin{array}{c}\text { void } \\
\text { ratio }\end{array}$ & $\begin{array}{c}\text { Friction } \\
\text { Coefficient } \\
\mu\end{array}$ & $\begin{array}{c}\text { shear } \\
\text { stiffness } \\
\mathrm{kn} / \mathrm{n} / \mathrm{m}\end{array}$ \\
\hline $\begin{array}{c}\text { parameter } \\
\text { values }\end{array}$ & 2600 & $\begin{array}{c}0.03 \sim \\
0.05\end{array}$ & 0.08 & 0.25 & $5 \times 10^{7}$ \\
\hline $\begin{array}{c}\text { Rock } \\
\text { parameters }\end{array}$ & $\begin{array}{c}\text { normal } \\
\mathrm{stiffness}\end{array}$ & $\begin{array}{c}\text { Parallel bond } \\
\text { shear } \\
\text { stiffness } \\
\mathrm{kn} /(\mathrm{n} / \mathrm{m})\end{array}$ & $\begin{array}{c}\text { Parallel bond } \\
\text { normal stiffness } \\
\mathrm{kn} /(\mathrm{n} / \mathrm{m})\end{array}$ & $\begin{array}{c}\text { viscous } \\
\text { damping } \\
\text { ratio }\end{array}$ \\
\hline $\begin{array}{c}\text { parameter } \\
\text { values }\end{array}$ & $1 \times 10^{5}$ & $5 \times 10^{7}$ & \multicolumn{2}{|c|}{$1 \times 10^{8}$} & 0.5 \\
\hline
\end{tabular}

TABLE II . THE PARAMETERS OF JOINT

\begin{tabular}{|c|c|c|c|}
\hline $\begin{array}{c}\text { the properties of } \\
\text { jointed rock mass }\end{array}$ & $\begin{array}{c}\text { normal stiffness } \\
\mathrm{kn} /(\mathrm{n} / \mathrm{m})\end{array}$ & $\begin{array}{c}\text { shear stiffness } \\
\mathrm{kn} /(\mathrm{n} / \mathrm{m})\end{array}$ & $\begin{array}{c}\text { friction coefficient } \\
\mu\end{array}$ \\
\hline parameter values & $1 \times 10^{3}$ & $1 \times 10^{3}$ & 0.15 \\
\hline
\end{tabular}

It must be said,the rock will break and start to move after applied the explosion load,to better react the attenuation that particles to stress wave in dynamic analysis, and make the processes of energy dissipating reflect real situation better, we set the local damping of particle at the blast area to zero,and activate the viscous damping.In addition,considering that the 
simulation space is semi-infinite space,and the reflection will be not allowed when stress wave transmit to the border of the model.So,we set the viscous damper of particle at a small area which we remove the free boundary of the other three boundaries to 1.0, and set all of the local damping to 0.7.Because of the energy would be the dissipated by the damping,Reflection phenomenon will not occur when the stress wave transmit to the border area.We take the section size of the rock blasting area is $20 \mathrm{~m} \times 12 \mathrm{~m}$,the depth of the explosive is $3 \mathrm{~m}$ in this case.In order to study the variety rule of pressure for explosive shock wave when the area near the shot-point is shocked,we set up monitoring points from the area near blasting source at different distances when the numerical simulation is beginning,the diagram of monitoring is shown in figure 5.

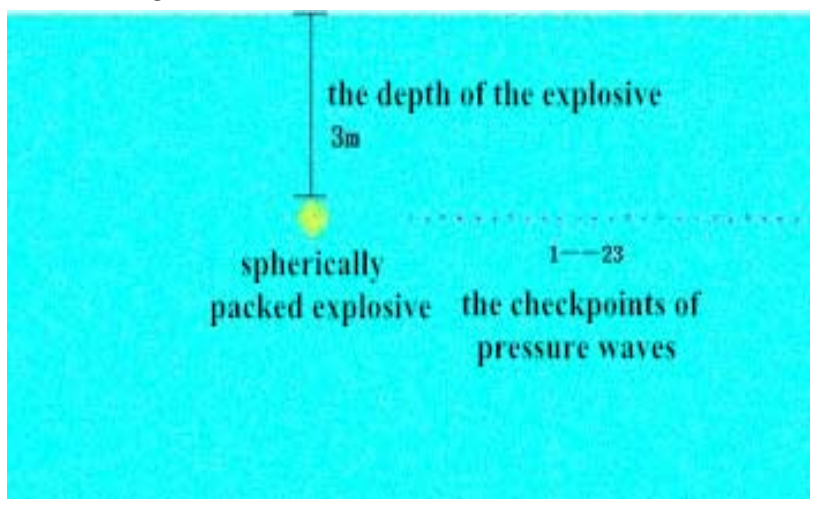

Figure 5. Charge Location and Monitoring Plan

\section{THE PROCEDURAL SIMULATION AND THEORETICAL ANALYSIS OF THE BLAST FOR NO-JOINTED ROCKS}

A. The Procedural Simulation of the Blast for No-jointed Rocks

Explosive blast wave will transmit to the rock near the explosive hole in the form of pressure waves after dynamite blast,the wave diagram of explosion stress wave for no-jointed rocks is shown in figure6(a) $(\mathrm{t}=2000)$ and (b) $(t=2000)$.We can see clearly that the shock waves start to transmit radially to deep rock mass by the spherical charge as the center after the explosion from the figure,and then forming a circle of spherical,with the increase of distance from the detonation point,the stress wave weakened gradually.

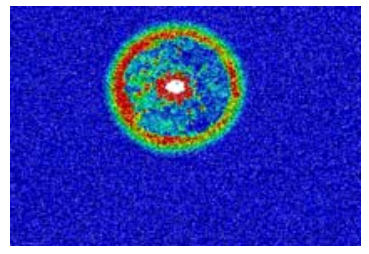

(a) $\mathrm{t}=\mathbf{2 0 0 0}$

Figure 6. No-joint Rock Explosion Stress Wave Propagation

Figure 7 is a scope map of the fracture zone.As the figure shows,the rock fracture zone will be formed above concentrated charges after the blast,and the rock near the shot-point will produce the phenomenon of radial compression,and this will cause the expansion of the rock mass; When the tensile strength of the rock is bigger than the extensional stress of the rock,the rock mass will crack until expansion stress is less than the tensile strength,the radius of kibbling area is roughly 3 times that of the radius of blasting.

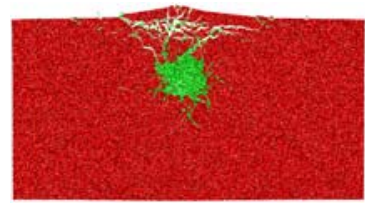

(a) Broken an Explosive Source Area

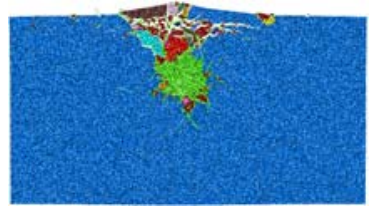

(b) Blasting Upper Broken Zone
Figure 7 . Broken Blasting Area

The potential of internal blast convert quickly into mechanical energy, thermal energy, light, radiant energy etc. in the process.One of the most significant function is that it transmit speed, detonation pressure to the medium near the shot-point promptly in the form of vibration response, then it does work on the surrounding media and causes the surrounding media to destroy. With the increase of distance from the blasting point, the remaining energy can not destroy the surrounding rock,that only leads to elastic vibration in rock particle until the vibration energy is totally absorbed by the rock.As the growth of the preservative process,the pressure of the stress wave decline sharply until the pressure waves from exploding disappear gradually.

The figure 8(b) is a blasting funnel which is obtained by numerical simulation,and the figure 8(b) is theoretical blasting funnel.We can see clearly that the theoretical value is in conformity with the emulation value from the figures.

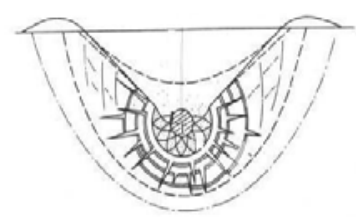

(a) The Theory of Blasting Funnel

Figure 8. Blasting Funnel

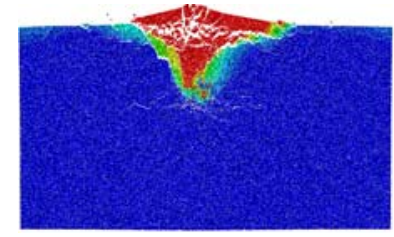

(b) The Numerical Simulation of Blasting Funnel

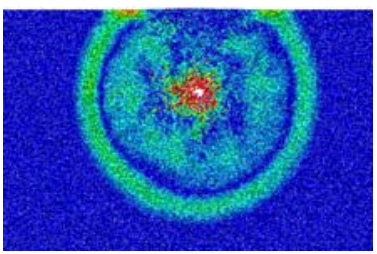

(b) $t=4000$

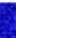

B. The Attenuation Law of Explosion Stress Wave for No-jointed Rocks

Rock mass is similar to the infinite medium,the peak of blast wave must be attenuated when it transmit in the rock mass,the farther distance the rock particle from the blasting source, the more attenuation. of the peak.Based on the relevant research findings ${ }^{[6,7]}$,we can get the following formula which can know the law of peak for blast stress wave. 


$$
P_{\mathrm{r}}=P_{d}\left(\frac{d}{r}\right)^{3}
$$

In the formula ${ }^{[8]}: \mathrm{Pr}$ is the peak pressure of detonation waves that in a rock interface which at any distance from explosive source in rock mass $(\mathrm{Pa}), \mathrm{Pd}$ is the initial impact of rock interface in the hole wall(Pa), $\mathrm{d}$ is the diameter of charge(m), $\mathrm{r}$ is the distance from rock interface to blast source(m),We set the radius of charge to $0.2 \mathrm{~m}$, the initial impact to 50Mpa.

The Figure 9 is the time-history curve of explosion stress wave about every monitoring point which we have set in the simulation analysis. The Figure 10 is the theoretical attenuation curve of the change between the pressures peak of rock and the distances from center of explosion which is figured out by Formula 1 and is obtained by simulation analysis ${ }^{[9]}$.The Figure is plotted by the ratio of the measuring point distance from explosion sources to the diameter of charge as X-axis and the peak pressure of explosion as Y-axis. According to Formula 1 and the peak pressure of explosion for every measuring point,we can obtain the attenuation curve of theory and numerical simulation about the pressures peak of rock and the distances from center of explosion ${ }^{[10]}$. Through comparisons,we can know that the result of the attenuation about the pressures peak of rock which we are obtained by numerical simulation and theoretical calculation are largely consistent. This illustrates that the process of stress attenuation which we are obtained by numerical simulation is believable.
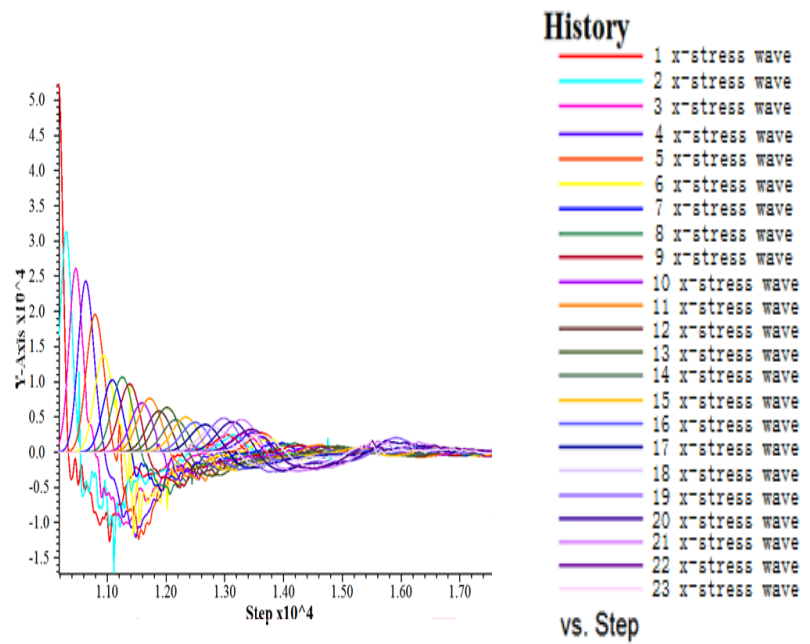

Figure 9. Each Testing Point Stress Time History Curve

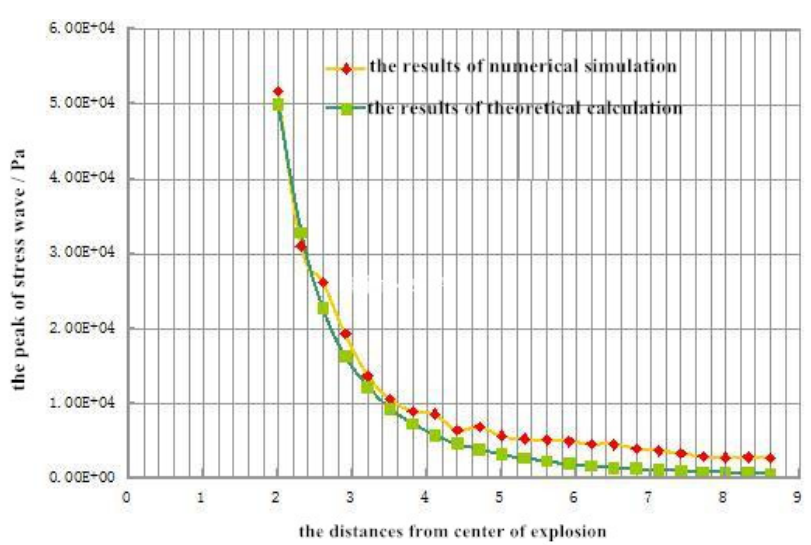

Figure 10. Blasting Stress Wave Attenuation Curve

\section{CONCLUSIONS}

1) According to the present research, we can emulate propagation of dynamic stress by blasting we 11.

2) PFC2D not only can investigate the explosion process from the microscopic view,but also can overcame many questions,such as:large deformation of rock mass,material nonlinear,FEM numerical simulation can not simulate the fragmentation of rock mass, and so on.

3) We do not need to specify the constitutive relationship of soil, simply assign the particles-related parameters. Modeling process is relatively simple, what's more, the result of numerical simulation and theoretical calculation are largely consistent.

\section{THE SHORTAGE AND PROSPECTS}

1) The degree of precision about numerical simulation for particles flow depends largely on the micro parameters of the model in geotechnical engineering, and there is no an obvious positive correlation between the micro parameters and the macro-response of the mode at present,And so comparison and quantitative analysis will be hard to do.

2) In order to improve the ability that the dispersion unit simulate and analyze practical engineering,the research on the relationship between the micro-mechanism and macro phenomena,and the analysis of model reliability need a further improcement.

\section{REFERENCES}

[1] Wang Ming-yang,Qian Qi-hu.The attenuation law when the explosive stress wave transmit joint fissures[C].Selections from Academician Qian Qi-hu's theses,pp.335-340.

[2] Zhang Ji-hong,Liu Hong-yan, The numerical simulation about the influence between jointed properties and the failure mode of the rock mass blasting[J].Blast,2013,pp.79-83.

[3] Li Xue-ye,Liu Jian-feng,Qin Li.The experimental study about the law of energy dissipation when stress transmit rock joint.2011,pp.85-90.

[4] Abdellah Hafsaoui,Korichi Talhi.Influence of joint direction and position of explosive charge on fragmentation[J].The Arabian Journal for Science and Engineering,2008,pp.125-132.

[5] Y ju, SUDAK L, XIE H P. Study on stress wave propagation in fractured rocks with fractal joint surfaces[J]. International Journal of Solids and Structures,2007,pp.256-271. 
[6] Gao Jin-shi,Zhang Ji-chun.The dynamic analysis about the mechanism of rock fragmentation in the explosion.Metal Mines,1989,pp.7-12.

[7] Dai Jun.The calculation of cracked zone and crushing circle column charge in rock.The University Journal of the Liaoning Engineering Technology University(JCR-SCI),2001,pp.144.

[8] M. S. Khan, J. Prasad,Effect of High Temperature on High-Volume Fly Ash Concrete[J]. Arabian Journal for Science and Engineering, 2013,38(6).

[9] D. B. Kulkarni,, Comparative Study of Effect of Sustained High Temperature on strength Properties of Self Compacting Concrete and Ordinary Conventional Concrete[J]. International Journal of Engineering and Technology,2011,3(2).

[10] Shamsad Ahmad, Saeid A. Alghamdi. A Study on Effect of Coarse Aggregate Type on Concrete Performance[J]. Arabian Journal for Science and Engineering, 2012, 37(7). 